\title{
Apoptosis Induction by the 5' NCR of Infectious Bursal Disease Virus
}

\author{
Renmao Li, Haiying Wang and Manfu Zhang* \\ Laboratory for Animal Molecular Virology, College of Biological Sciences, China Agricultural University, Beijing \\ 100094, China
}

\begin{abstract}
Virus invasion and replication can induce apoptosis and play an important role in the life cycle of viruses. To illustrate the relationship between apoptosis induction and the non-coding region (NCR) of infectious bursal disease virus (IBDV), the $5^{\prime}$ NCR of Harbin-1 (a very virulent IBDV) segment A was sequentially deleted using PCR and exchanged with the corresponding region of the mild virulent strain $\mathrm{Cj} 801$. IBDV mutants were recovered using a reverse genetics system and named $\mathrm{H} \Delta 35, \mathrm{H} \Delta 74, \mathrm{H} \Delta 94$, and HCA. Apoptosis in chicken embryo bursal cells was then determined by flow cytometry. The results revealed that the IBDV mutants could induce apoptosis, but with varying capability. As the length of the deleted sequence increased, the capacity to induce apoptosis decreased. However, there was no marked difference in apoptosis induction between $\mathrm{H} \Delta 35$ and $\mathrm{H} \Delta 74$. The above results indicate that the NCR may increase the ability to induce apoptosis. Quantitative nested real-time PCR was performed to illustrate the relationship between replication and apoptosis. The result showed an obvious positive correlation for $\mathrm{H} \Delta 35$ and HCA but an independent process for $\mathrm{H} \Delta 74$ and $\mathrm{H} \Delta 94$.
\end{abstract}

Keywords: Apoptosis induction, flow cytometry assay, NCR deletion of IBDV, quantitative real time PCR.

Infectious bursal disease virus (IBDV) is a nonenveloped virus with a small double-stranded segmented RNA genome belonging to the family Birnaviridae [1]. IBDV is classified into serotypes I and II based on serological response. In chickens, serotype I is pathogenic and causes lymphocyte depletion in the bursa of Fabricius (BF), while serotype II is non-pathogenic [2]. Nieper et al. showed that the virus particles for serotype I bind to the lymphocytes in BF, spleen, and thymus like those of serotype II, suggesting that the tropism of IBDV for lymphocyte cells is not decided by the existence of a specific receptor but by another regulating factor, possibly related to the regulation of replication [3]. The regulation of replication is governed by multiple factors such as the $5^{\prime}$ non-coding region (NCR), $3^{\prime}$ NCR, and stability of mRNA.

Different NCRs of viruses might play important roles in regulation. An internal ribosome entry site (IRES) was detected in the $5^{\prime} \mathrm{NCR}$ of picornavirus. The IRES was necessary for cap-dependent virus translation, and the predicted tertiary structure suggested a possible binding site for human 18S RNA [4]. The conservative sequences in $5^{\prime}$ and $3^{\prime}$ NCRs of eight influenza viruses were necessary for nuclease activity [5]. Furthermore, an enhancer and enhancer-regulating region and binding sites for the CCAAT-binding transcription factor NF-Y were identified inside the NCR [6]. Mundt et al. sequenced and cloned the 5' and $3^{\prime}$ NCRs of both segments of several serotype I strains and one serotype II strain [7]. Their secondary structure showed significant differences between the two serotypes, among which the 5' NCR in serotype I had a Y-shaped stem-

*Address correspondence to this author at the Laboratory for Animal Molecular Virology, College of Biological Sciences, China Agricultural University, Beijing 100094, China;

Tel: +861062732662; Fax: +861062731055;

E-mail: Manfuzhang@yahoo.com loop structure, but serotype II had a stem-loop structure shaped like a "1"; moreover, inverted terminal repeats were detected in the $5^{\prime}$ and $3^{\prime}$ NCRs and were possibly related to the formation and maintenance of a hairpin-loop structure. The $5^{\prime}$ NCRs of both serotypes had a promoter consisting of conservative 32-nucleotide and IRES region. The initial two bases were GG in the $5^{\prime}$ NCR; VPg can bind one or two Gs covalently and prime the synthesis of sense and antisense strands using protein as the primer when there is no genome template [8]. If the structural difference is related to virulence and the capacity to induce apoptosis, this relation has not yet been reported.

IBDV infection results in lymphoid depletion and marked atrophy of the BF, suggesting the induction of apoptosis [9]. Apoptosis processes affect the pathogenesis of IBD. The induction of apoptosis has been reported in peripheral blood lymphocytes [10, 11], Vero cells, and chicken embryo (CE) cells [12]. The apoptotic process is possibly due to the interaction between IBDV infected and non-infected cells, suggesting that infection is not a prerequisite for the induction of IBDV apoptosis [13]. VP5 and VP2 have been demonstrated to be apoptosis inducers $[14,15]$. It is hypothesized that VP4 may be involved in an apoptotic signal during virus replication; however, Rodriguez-Lecompte et al. demonstrated that VP4 of IBDV serotypes I and II did not induce apoptosis in the chicken B-lymphocyte cell line DT-40 [16].

Apoptosis is related to virulence because apoptosis can lead to immunosuppression. To date, research about virulence and apoptosis has focused on VP1, VP2, VP3, VP4, and VP5. There have been fewer reports of the function of NCRs and the relationship between NCRs and virulence in regard to apoptosis. Furthermore, research findings have differed largely in regard to the relationship between viral replication and apoptosis. Tham et al. suggested that apoptosis and virus replication are independent processes 
[12]. However, Jungmann et al. found a correlation between the proportion of apoptotic cells and IBDV replication [13]. In 2002, the full-length nucleotide sequence of the genome for the very virulent IBDV (vvIBDV) Harbin-1 was obtained, and $5^{\prime}$ and $3^{\prime}$ end sequences were analyzed; the result showed that the $5^{\prime} \mathrm{NCR}$ of segment A contained a promoter and IRES region. However, the function of other regions in the $5^{\prime} \mathrm{NCR}$ is still unknown. In this study, we examined the relationship between the 5' NCR of segment A and apoptosis. We also investigated the role of the $5^{\prime} \mathrm{NCR}$ in IBDV replication efficiency by deleting the promoter and the interspace between the promoter and the IRES, and exchanging the $5^{\prime} \mathrm{NCR}$ with the corresponding region of the mild virulence strain $\mathrm{Cj} 801$.

\section{MATERIALS AND METHODS}

\section{Viruses and Cells}

The vvIBDV strain Harbin-1 was provided by the Harbin Veterinary Research Institute of the Chinese Academy of Agricultural Sciences. When specific-pathogen-free (SPF) chickens were inoculated with Harbin-1 at a dose of $2 \times 10^{3}$ EID $_{50}, 60 \%$ mortality resulted. In contrast, the cell-adaptable strain Cj801 caused $0 \%$ mortality when given to SPF chickens at a dose of $2 \times 10^{3}$ EID $_{50}$. Primary bursal cells were derived from 18-day-old embryonated SPF eggs (Merial, Beijing, China) and grown in Dulbecco's modified Eagle's medium (DMEM, Sigma Aldrich, St. Louis, MO, USA) supplemented with $10 \%$ fetal calf serum (FCS) and maintained with DMEM containing 5\% FBS. Transfection experiments were performed on primary bursal cells.

\section{Polyadenylation of dsRNA and Amplification of 3 ' Ends}

Isolation of viral RNA was performed with a MiniBest viral RNA/DNA extraction kit according to the manufacturer's protocol (Takara Biotechnology, Dalian, China). The 3' termini of both strands of segments A and B were polyadenylated following the protocol described by Mundt [7]. The polyadenylation reaction mixture $(50 \mu \mathrm{l})$, consisting of $1 \mu \mathrm{g}$ viral RNA, $50 \mathrm{mM}$ Tris- $\mathrm{Cl}$ ( $\mathrm{pH} 7.9), 10$ $\mathrm{mM} \mathrm{MgCl} 2,250 \mathrm{mM} \mathrm{NaCl}, 0.25 \mathrm{mM}$ adenosine triphosphate (ATP), $2.5 \mathrm{mM} \mathrm{MnCl}_{2}, 250 \mu \mathrm{g}$ bovine serum albumin (BSA), and 1 unit poly(A) polymerase (Invitrogen, Carlsbad, CA, USA), was added and incubated for 20 minutes at $37^{\circ} \mathrm{C}$. Next, poly(A) RNA was extracted using equal volumes of phenol and chloroform and recovered by ethanol. Reverse transcription was performed using Oligo (dT) as the primer following the protocol given for Invitrogen's 3'-RACE kit with minor alteration. PCR was performed using P1 (segment A) and P2 (segment B) as the primers (Table 1). The PCR profile was as follows: 1 cycle of $94^{\circ} \mathrm{C}$ for $4 \mathrm{~min}$ and 30 cycles of $94^{\circ} \mathrm{C}$ for $30 \mathrm{~s}, 55^{\circ} \mathrm{C}$ for $30 \mathrm{~s}$, and $72^{\circ} \mathrm{C}$ for $10 \mathrm{~s}$.

\section{Amplification of the 5' Ends}

Amplification of the $5^{\prime}$ ends followed the method described by Frohman [17], with minor modifications, using Invitrogen's $5^{\prime}$-RACE reaction kit. Briefly, purified viral RNA was denatured at $98^{\circ} \mathrm{C}$ for $5 \mathrm{~min}$, and then the first strand of cDNA was synthesized using reverse transcriptase superscript II (Invitrogen) with the P3 and P6 primers (Table 1). cDNA was purified by column chromatography (Invitrogen) and tailed by poly(C) using terminal deoxynucleotidyl transferase (TdT, Invitrogen). The cDNA was then amplified with P4/P5 (segment A) and P7 (segment B) primers and an anchor primer (provided as part of the kit). The PCR profile was as follows: segment A: 1 cycle of $94^{\circ} \mathrm{C}$ for 5 min and 35 cycles of $94^{\circ} \mathrm{C}$ for $30 \mathrm{~s}, 58^{\circ} \mathrm{C}$ for $30 \mathrm{~s}$, and $72^{\circ} \mathrm{C}$ for $30 \mathrm{~s}$; segment B: 35 cycles of $94^{\circ} \mathrm{C}$ for $30 \mathrm{~s}, 63^{\circ} \mathrm{C}$ for $30 \mathrm{~s}$, and $72^{\circ} \mathrm{C}$ for $30 \mathrm{~s}$.

\section{Cloning of NCR PCR Fragments and Sequencing}

PCR fragments were recovered by glassmilk after electrophoresis in $1.5 \%$ agarose gels and ligated into the pGEM-T vector (Promega, Madison, WI, USA). A positive clone was obtained using X-gal and IPTG: $\alpha$ complementation as described by Sambrook [18] and identified by PCR after transforming Escherichia coli strain DH5 $\alpha$. Both strands of respective inserts were sequenced by Takara Biotechnology in Dalian of China and Shanghai Sangon Biological Engineering Technology and Services Co., Ltd. in China.

\section{Construction of Full-Length cDNA Clones Using Fusion PCR}

Segments A and B of the Harbin-1 clone included six clones, including the coding region (CR) of segments $A$ and $\mathrm{B}$, designated as pGEM-T-HA and pGEM-T-HB, respectively, and the NCRs of segments A (pGEM-T-H5'A and pGEM-T-H3'A) and B (pGEM-T-H5'B and pGEM-TH3'B) (Table 2) [19, 20]. All recombinant plasmids were based on pGEM-T (Promega). There was an area of partial overlap between the $\mathrm{CR}$ clone and the $\mathrm{NCR}$ clone for

Table1. Primers Used for Cloning of 5'and 3'Non-Coding Regions

\begin{tabular}{|c|l|c|c|}
\hline Primer & Sequence & Position & Terminal \\
\hline \hline P1 & CCCAATGCTCCAACACAGAGAC & $+^{\mathrm{a}}(\mathrm{nt} 3092-3113)$ & 3'segA \\
\hline P2 & CGCCAAAAGGAGAGCCGCTAA & $+(\mathrm{nt} 3178-3196)$ & 3 'segB \\
\hline P3 & TTGAGCCAGGGAAACCAGGG & $-{ }^{\mathrm{b}}(\mathrm{nt} 310-330)$ & 5 'segA \\
\hline P4 & CTGACCTGAGAGTGTGCTTC & $-(\mathrm{nt} 232-251)$ & 5 'segA \\
\hline P5 & GATCTTGCAGGTTCGTCATCGC $130-150)$ & 5'segA \\
\hline P6 & GTCGGTCTCATACTCCTCATTC & $-(\mathrm{nt} 318-340)$ & 5 'segB \\
\hline P7 & AGGGCTGGCAAGCGGATCCT & $-(\mathrm{nt} 248-268)$ & 5 'segB \\
\hline
\end{tabular}


segments $\mathrm{A}$ and $\mathrm{B}$. The overlapped area lacked an appropriate restriction site; thus fusion PCR was used to ligate the NCR and CR to obtain a full-length cDNA clone for segments A and B. Oligonucleotides HACR1, HACR2, HANCR1, HANCR2, HBCR1, HBCR2, HBNCR1, and HBNCR2 were used for segments A and B (Table 3). For transcription in vitro, the EcoRI site and $\mathrm{T} 7$ promoter were introduced into the $5^{\prime}$ end of the oligonucleotides, the XbaI site at the $3^{\prime}$ end in segment A, and the XhoI site at the $3^{\prime}$ end in segment B. The fusion PCR product of segment A was ligated into the pMD-18T-simple vector (Takara Biotechnology) to obtain full-length cDNA of the segment A clone, which was named pRHA.

Because 52 bps at the $3^{\prime}$ extreme end of the $3^{\prime}$ non-coding region of segment $B$ were truncated [19], a series of oligonucleotides including HBRA1, HBRA2, and HBRB to HBRE (Table 3) was designed to fill in the $3^{\prime}$ extreme end by use of consecutive PCR and the primer walking method. The fusion PCR product was ligated into the pMD-18T-simple vector (Takara Biotechnology) to obtain the full-length clone of segment B, named pRHB, under the control of the T7 promoter.

Table 2. Plasmids Used for Fusion PCR and their Characteristics

\begin{tabular}{|c|c|}
\hline Plasmid & Main Feature \\
\hline \hline pGEM-T-HA & Harbin-1A segment coding sequence \\
pGEM-T-HB & Harbin-1B segment coding sequence \\
pGEM-T-H5'A & Harbin-1A segment5' non-coding sequence \\
pGEM-T-H3'A & Harbin-1A segment3' non-coding sequence \\
pGEM-T-H5'B & Harbin-1B segment5' non-coding sequence \\
pGEM-T-H3'B & Harbin-1B segment3' non-coding sequence \\
\hline
\end{tabular}

Table 3. Oligonucleotides Used for Amplification of Serotype I Strain of Harbin-1 Sequences

\begin{tabular}{|c|c|c|c|}
\hline \multicolumn{4}{|l|}{ Oligonucleotide Qrientation Position Name } \\
\hline$\frac{\text { CTCCTCCTTCTACAACGCTATCAT }}{\text { XbaI }}$ & sense & $71-924$ & HACR 1 \\
\hline $\begin{array}{l}\text { GAATCTAGAGGGGACCCGCGAACG } \\
\text { EcoRI }\end{array}$ & antisense & $3246-3261$ & HACR2 \\
\hline GGAATTCTAATACGACTCACTATAGGGGGGATACGATCGGTCTG & sense & $1-16$ & HANCR1 \\
\hline GATCTTGCAGGTTCGTCATCGC & antisense & 128-149 & HANCR2 \\
\hline TGGCTACTAGGGGCGATGC & sense & $42-60$ & HBCR 1 \\
\hline$\frac{\text { CTTCTTGAGTGGTTCCCATC }}{\text { EcoRI }}$ & antisense & $2756-2775$ & HBCR2 \\
\hline GGAATTCTAATACGACTCACTATAGGATACGATGGGTCTGACCCT & sense & $1-21$ & HBNCR1 \\
\hline$\frac{\text { GTCACTCATGGTGGCAGAATCAT }}{\text { EcoRI }}$ & antisense & $98-120$ & HBNCR2 \\
\hline GGAATTC $T A A T A C G A C T C A C T A T A \underline{\text { GGATACGATGG }}$ & sense & $1-11$ & HBRA1 \\
\hline GGTCTGGGGTTAGTGTCCTCTTCTTGAGTGGTTCCCATC & antisense & $2756-2794$ & HBRA2 \\
\hline GGCCGGGGATACGGGGTCTGGGGTTAGTGTCCT & antisense & $2776-2808$ & HBRB \\
\hline GCAGGCGAAGGCCGGGGATACGGGGTC & antisense & $2791-2817$ & HBRC \\
\hline$\underline{\text { CCGCAGGCGAAGGCCGGGGAT }}$ & antisense & 2799-2819 & HBRD \\
\hline$\frac{\text { GCCCCCGCAGGCGAAGG }}{\text { Xhol }}$ & antisense & $2807-2823$ & HBRE \\
\hline $\begin{array}{l}\text { CTCGAGGGGGCCCCCGCAGGCGAAG } \\
\text { EcoRI }\end{array}$ & antisense & $2808-2827$ & HBRF \\
\hline $\begin{array}{l}\text { GGAATTCTAATACGACTCACTATAGACCCGGGGACAGGCT } \\
\text { EcoRI }\end{array}$ & sense & 35 & PD35 \\
\hline $\begin{array}{l}\text { GGAATTCTAATACGACTCACTATAGCTCCTCCTTCTACAATG } \\
\text { EcoRI }\end{array}$ & sense & 74 & PD74 \\
\hline $\begin{array}{l}\text { GGAATTCTAATACGACTCACTATAGTCATTGATGGTCAG } \\
\text { EcoRI }\end{array}$ & sense & 94 & PD94 \\
\hline $\begin{array}{l}\text { GGAATTCTAATACGACTCACTATAGGATACGATCGGTCTGACCCGG } \\
\text { XbaI }\end{array}$ & sense & 1 & PCA \\
\hline GAATCTAGA $\underline{\text { GGGGACCCGCGAACG }}$ & antisense & 3176-3199 & PDA \\
\hline TAACCGTCCTCAGCTTACCC & sense & $625-644$ & outside 1 \\
\hline TCAGGATTTGGGATCAGCTC & antisense & $1250-1267$ & outside 2 \\
\hline CCAACCAGCGAGATAACC & sense & $1023-1040$ & inside 1 \\
\hline GGCGACCGTAACGACAG & antisense & $1216-1232$ & inside 2 \\
\hline
\end{tabular}

The restriction sites used are given in bold text and the appropriate restriction enzymes are named. Underlined nucleotides are virus-specific. The T7 promoter is shown in italics. The positions where the primers bind (nucleotide number) are in accordance with the sequence of strain P2 (7). 


\section{Construction of the $5^{\prime}$ NCR Mutant}

A series of oligonucleotides was designed for deletion of the $5^{\prime} \mathrm{NCR}$ in segment A. Deletion mutants were obtained using PCR and sequenced by the Takara Biotechnology and Sangon companies. In addition, the NCR of Harbin-1 segment A was exchanged with the attenuated IBDV strain Cj-801 NCR (data not show) using fusion PCR. Table 3 lists the oligonucleotides used for the deletion.

\section{Transcription and Transfection of Synthetic RNAs}

Plasmids pMD-18HA and pUC18-CA and their mutant clones pMD18 35 , pMD18 $\Delta 74$, pUC18 $\Delta 94$, and pMD18RHB were digested with XbaI and XholI, respectively, and used as templates for transcription in vitro with T7 RNA polymerase (Promega). Briefly, restriction enzyme cleavage assays were adjusted to $0.5 \%$ sodium dodecyl sulfate (SDS) and incubated with proteinase $\mathrm{K}(0.5 \mathrm{mg} / \mathrm{ml})$ for $1 \mathrm{~h}$ at $37^{\circ} \mathrm{C}$. The linearized DNA templates $(1 \mu \mathrm{g})$ were recovered after ethanol precipitation and were added to transcription reaction mixtures $(50 \mathrm{ml})$ containing $40 \mathrm{mM}$ Tris- $\mathrm{HCl}(\mathrm{pH} 7.9), 10$ $\mathrm{mM} \mathrm{NaCl}, 6 \mathrm{mM} \mathrm{MgCl}$, $2 \mathrm{mM}$ spermidine, $0.5 \mathrm{mM}$ ATP, $0.5 \mathrm{mM}$ cytidine triphosphate (CTP), $0.5 \mathrm{mM}$ uridine triphosphate (UTP), $0.1 \mathrm{mM}$ guanosine triphosphate (GTP), $0.25 \mathrm{mM}$ cap analog $\left[\mathrm{m}^{7} \mathrm{G}\left(5^{\prime}\right) \mathrm{ppp}\left(5^{\prime}\right) \mathrm{G}\right]$ (Promega), 120 units ribonuclease inhibitor (Takara Biotechnology), and 150 units T7 RNA polymerase (Promega), and incubated at $37^{\circ} \mathrm{C}$ for $1 \mathrm{~h}$. Synthetic RNA transcripts were purified by phenolchloroform extraction and ethanol precipitation. As controls, the transcription products were treated with either DNase or RNase (Promega) before the purification step.

Primary bursal cells of chicken were prepared according to standard protocols and maintained at $37^{\circ} \mathrm{C}$ and $5 \% \mathrm{CO}_{2}$ atmosphere in DMEM supplemented with 5\% FCS. After primary bursal cells were grown to $80 \%$ confluency in $35-$ $\mathrm{mm}$ dishes, the cells were washed twice with DMEM (serum-free) and incubated at $37^{\circ} \mathrm{C}$ for $10 \mathrm{~min}$ after each wash in $\mathrm{CO}_{2}$ incubator. Simultaneously, $60 \mu \mathrm{D}$ DMM was incubated with $6 \mu 1$ of Lipofectin reagent (Invitrogen) for 60 min in a polystyrene tube at room temperature to form a Lipofectin-DMEM mixture. Synthetic RNA transcripts of both segments resuspended in $30 \mu \mathrm{l}$ of water treated with diethylpyrocarbonate (DEPC) were added to the DMEMLipofectin mixture, mixed gently, and incubated on ice for 5 min. After removing the DMEM from the monolayer cells in the $35-\mathrm{mm}$ dishes and replacing it with $800 \mu \mathrm{l}$ of fresh DMEM, the nucleic acid-containing mixture was added drop-wise to the cells and swirled gently. After $2 \mathrm{~h}$ of incubation at $37^{\circ} \mathrm{C}$, the mixture was replaced with DMEM containing 5\% FCS (without rinsing the cells) and further incubated at $37^{\circ} \mathrm{C}$ for desired time intervals.

\section{Virus Recovery from cRNA and Identification}

Two days after transfection, cells were frozen-thawed three times and centrifuged at $700 \times g$ to remove cellular debris. The supernatant was passaged four times in the primary bursal cells. To screen the recombinant virus from a large quantity of samples, antigen-capture enzyme-linked immunosorbent assay (AC-ELISA) was performed using a monoclonal antibody, Mab6 [21]. If the optical density (OD) value of a sample was greater than the mean OD plus three times the standard deviation of the negative control sample, then the sample was considered to be positive and was stored at $-86^{\circ} \mathrm{C}$ for future use.

Part of the hypervariable region was amplified using nested real-time PRC (RT-PCR) to determine virus presence. If the target band appeared on the gel (209 bp), a positive result was obtained. Table 3 lists the primers including outside 1 , outside 2 , inside 1 , and inside 2 .

\section{Research on the Apoptosis Induced by Recombinant IBDV Induction}

\section{Sub-G $\sigma_{0} / G_{1}$ DNA Peak Technique}

Following the procedure described by Lam [22], 18 million primary bursal cells $\left(3 \times 10^{6} / \mathrm{ml}\right)$ were inoculated with $100 \mathrm{pfu}$ virus mutants. To quantify the number of apoptotic cells, infected and control bursal cells were collected at different time intervals, incubated with propidium iodide, and subjected to flow cytometry. Floating bursal cells and attached cells were removed from Petri dishes by trypsin treatment and collected in one tube by centrifugation; they were then washed with phosphate buffered saline (PBS) once and centrifuged to remove the PBS. The cells were fixed by $1 \mathrm{ml}$ ice-cold $70 \%$ ethanol and kept for $1 \mathrm{~h}$ at $4^{\circ} \mathrm{C}$ in ethanol. Ethanol was removed by centrifugation for $10 \mathrm{~min}$ at $300 \times g$. The pellet was resuspended in PBS for $5 \mathrm{~min}$. After the cells were filtered once with a 400-mesh screen, PBS was removed by centrifugation at $1000 \mathrm{rpm}$ for $5 \mathrm{~min}$. Next, $1 \times 10^{6}$ cells were incubated for $30 \mathrm{~min}$ at room temperature with $1 \mathrm{ml}$ propidium iodide $(50 \mu \mathrm{g} / \mathrm{ml}$ in PBS supplemented with $1 \%$ BSA and $40 \mu \mathrm{g} / \mathrm{ml}$ RNase A). The DNA content of the $1 \times 10^{6}$ cells was analyzed by flow cytometry. In the flow cytometry assay, propidium iodide produces red fluorescence with sub-ion fluorescence excitation. The wave length for excitation is $488 \mathrm{~nm}$ and the wave length for emission is greater than $630 \mathrm{~nm}$. The front-scatter light plot was analyzed against the side-scatter light plot. Compared with cells in the $G_{0} / G_{1}$ phase of the cell cycle, apoptotic cells appeared as a population of cells with a lower DNA content (sub- $\mathrm{G}_{0} / \mathrm{G}_{1}$ DNA peak technique) [23]. Cells to the left of the $\mathrm{G}_{0} / \mathrm{G}_{1}$ peak were therefore considered apoptotic. Each experiment was repeated at least three times.

\section{Measurement of the Apoptosis Index}

Measurement of the apoptosis index was performed using the procedure described by Duke and Cohen with minor modifications [24]. First, $5 \mu 1$ of ethidium bromide and acridine orange were added to $100 \mu \mathrm{l}$ of the abovementioned cells $\left(10^{6} / \mathrm{ml}\right)$. The mixture was mixed well and incubated for 20-30 $\mathrm{min}$ at room temperature; $50-60 \mu \mathrm{l}$ of the mixture were then added to a slide, sealed with a cover glass, and observed with a fluorescent microscope using excitation filters BG12 and BV and a $515 \mathrm{~nm}$ or SP3 interdiction filter. Each sample was observed in ten visual fields and the mean value was obtained. The apoptosis index is represented as the number of apoptotic cells per 100 bursal cells.

\section{Plaque Assay of Recombinant Virus [25]}

The titer of virus was determined using a plaque assay and expressed as PFU/ml. 


\section{Characterization of IBDV Mutants in the Cell Culture}

To assay the replication of IBDV mutants, quantitative nested RT-PCR was performed. Eighteen million primary bursal cells were inoculated with IBDV mutants and Harbin1 at the same titer and incubated for 5 days at $37^{\circ} \mathrm{C}$ in a $5 \%$ $\mathrm{CO}_{2}$ incubator. The cells were collected, frozen and thawed three times, and the resulting supernatant was used for isolating viral RNA. Viral RNA was extracted with a viral RNA/DNA extraction kit (Takara) following the manufacturer's instructions. Conventional RT-PCR was performed; the first PCR was amplified with outside 1 and outside 2 primers (Table 3 ). The second PCR was performed with inside 1 and inside 2 primers (Table 3 ). The second PCR products were detected by electrophoresis through a $1 \%$ agarose gel stained with ethidium bromide and visualized under UV light. If there was no primer dimer and nonspecific bands appeared, then the first PCR products could be used as the template for the quantitative nested RT-PCR. Quantitative RT-PCR was performed by the SYBR Green I method and determined by absolute quantification using the inside 1 and inside 2 primers (Table 3 ). The quantitative nested RT-PCR protocol was $94^{\circ} \mathrm{C}$ for 5 min; 40 cycles of $94^{\circ} \mathrm{C}$ for $30 \mathrm{~s}, 60^{\circ} \mathrm{C}$ for $30 \mathrm{~s}, 72^{\circ} \mathrm{C}$ for $30 \mathrm{~s}$; and $72^{\circ} \mathrm{C}$ for 10 min. The cycle threshold $(\mathrm{Ct})$ values were measured in triplicate. Regression analysis of the mean values of three replicates for the log-10 diluted pRHA was used to generate standard curves. The coefficient of variance for three replicates was calculated for the IBDV specific reactions. The reproducibility of the assay was tested by analysis of variance (ANOVA) comparing repeated runs of samples, and mean values generated at individual time points were compared using Student's $t$-test using SPSS 11.5 software.

\section{RESULTS}

\section{Identification of the Recombinant Plasmid}

The mutant clones were designated pUC-CA, pMD18HA, pMD-18 $\Delta 35$, pMD-18 $\Delta 74$, and pMD-18 $\Delta 94$ (Table 4). The abovementioned plasmids were digested by EcoRI and $\mathrm{XbaI}$ to produce the expected bands of 3.2 and $2.7 \mathrm{~kb}$, respectively, and mutant clones of segment A were obtained.

\section{Identification of Full-Length Segment A}

The ligation between coding and non-coding regions was only identified by sequencing because the NCRs were so

short that they could not be identified by restriction enzyme digestion. The part linking the deleted NCR and CR was sequenced, and the results are given in Fig. (1).

\section{RNA Synthesis In Vitro and Recovery of Virus}

The deletion mutant clones for full-length cDNA of segments $\mathrm{A}$ and $\mathrm{B}$ were linearized by XbaI and XhoI, respectively. The linearized plasmid was recovered and used as the template for transcription. Plus-sense RNA was synthesized under T7 RNA polymerase, with $1.5 \mathrm{~kb}$ and 1.2 $\mathrm{kb}$ for segments $\mathrm{A}$ and $\mathrm{B}$, respectively.

Four virus mutants were screened from 30 samples by AC-ELISA. Their OD values were greater than the mean OD value plus three times the standard deviation of the negative control sample. The recovered virus mutants were designated rHarbin-1, HCA, $\mathrm{H} \Delta 35, \mathrm{H} \Delta 74$, and $\mathrm{H} \Delta 94$. The results indicated that the deletion mutant virus could be recovered without reference to partial or full deletion of the NCR.

\section{Bursal Cells Infected with IBDV Mutants Undergo Apoptosis}

Apoptotic cells appeared to the left of the $G_{0} / G_{1}$ cell cycle because fragmentation of genomic DNA resulted in the production of hypodiploid DNA. In infected cell cultures, the proportion of cells with lower DNA content increased considerably, indicating the induction of apoptosis. Apoptotic cells show typical hypodiploid peaks in histograms; namely, peaks appear to the left of the diploid peak (G1) and have characteristics of typical apoptotic cells at $48 \mathrm{~h}$ post infection (p.i.). The more apoptotic cells, the more evident the hypodiploid peak is. The percentages of apoptotic cells were as follows: $15.6 \%$ (rHarbin-1), $16.8 \%$ (HCA), $13.8 \%$ $(\mathrm{H} \Delta 35), 12.5 \%(\mathrm{H} \Delta 74), 11.7 \%(\mathrm{H} \Delta 94)$, and $6.0 \%(\mathrm{CK})$ at 48 h p.i. (Fig. 2). The number of apoptotic bursal cells in infected groups increased at 4-48 h p.i., but increased markedly at 8-48 h p.i. (Fig. 3). There were significant differences in the percentages of apoptosis cells among the infected groups, with HCA inducing a higher percentage of apoptosis than the other virus mutants.

The results indicated that the ability to induce apoptosis decreased as the deletion length of the NCR increased. Virus mutants with NCR deletion had a decreased ability to induce apoptosis relative to rHarbin-1 and HCA in which the NCRs remained intact; however, HCA had a slightly stronger ability to induce apoptosis than HA. The virus mutant HA $\Delta 94$, in which the NCR was totally deleted, had the least ability to induce apoptosis in the infected group. There was no marked difference in the abilities of $\mathrm{H} \Delta 35$ and $\mathrm{H} \Delta 74$ to induce apoptosis.

\section{Determination of the Apoptotic Index of Bursal Cells}

Infected and uninfected cells were stained with acridine orange and ethidium bromide. Apoptotic cells fluoresce orange, while normal cells fluoresce green under a

Table 4. The Characteristics of 5' NCR Harbin-1 Mutants

\begin{tabular}{|c|c|}
\hline Name & Characteristics \\
\hline pMD-18HA & Contains full-length $5^{\prime} \mathrm{NCR}$ \\
\hline pUC-CA & Contains full-length $5^{\prime}$ NCR of IBDV CJ-801; other sequence is the same as Harbin-1 \\
\hline pMD-18 1835 & Deleted promoter-like region in Harbin-1 NCR \\
\hline pMD-18 1874 & Deleted region between promoter-like region and internal ribosome entry site in $5^{\prime} \mathrm{NCR}$ of Harbin- 1 \\
\hline pMD-18 1894 & Deleted promoter-like region and ribosome binding site \\
\hline
\end{tabular}




\section{Segment A 5'end sequence}

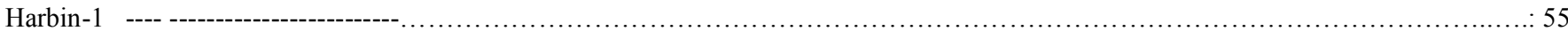

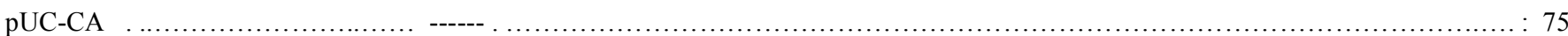

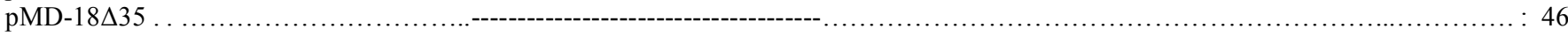

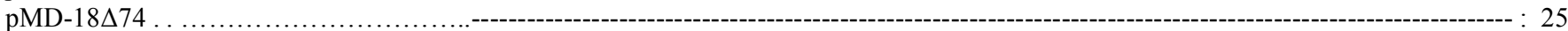

pMD-18 184 .. ........................... ---

GGAATTCTAATACGACTCACTATAGGGGGGATACGATCGGTCTGACCCCGGGGGAGTCACCCGGGGACAGGCTGACAAGG

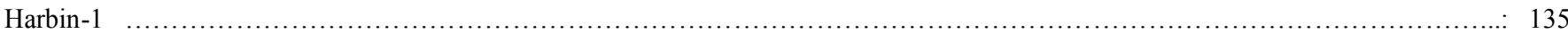

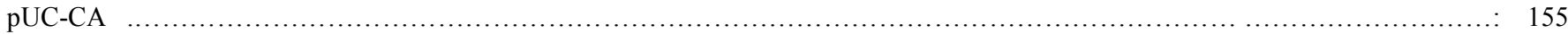

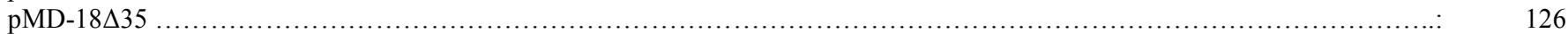

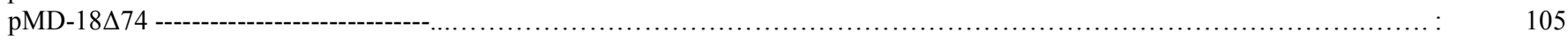

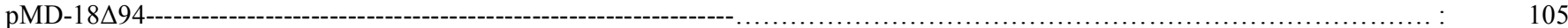

CCTTGTTCCAGGATGGAACTCCTCCTTCTACAATGCTATCATTGATGGTCAGTAGAGATCAGACAAACGATCGCAGCGAT

Fig. (1). Nucleotide sequence alignment of the $5^{\prime}$ NCRs of segment A and the NCR deletion of Harbin-1. Dashes indicate residues different from Harbin-1 in pUC-CA and deleted residues in pMD-18 $\Delta 35$, pMD-18 $\Delta 74$, and pMD-18 $\Delta 94$.

fluorescent microscope. The percentage of apoptotic cells in the infected group increased rapidly, corresponding to the flow cytometry results at $4-48 \mathrm{~h}$ p.i. (Fig. 4). The infected and control groups had significantly different percentages of apoptotic cells during the $4-48 \mathrm{~h}$ period $(p<0.05)$. The ability of the virus mutants and rHarbin-1 to induce apoptosis differed significantly $(p<0.05)$, but there was no difference between $\mathrm{H} \Delta 35$ and $\mathrm{H} \Delta 74(p>0.05)$ (Table 5).

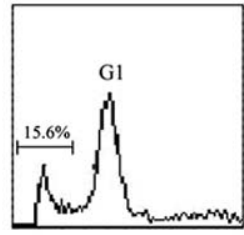

rHarbin-1
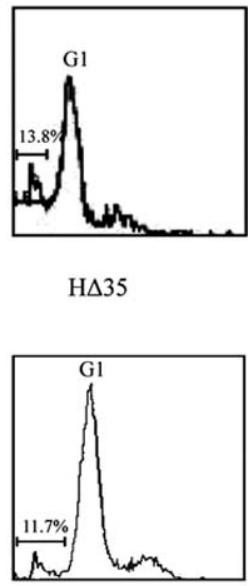

$\mathrm{H} \Delta 94$

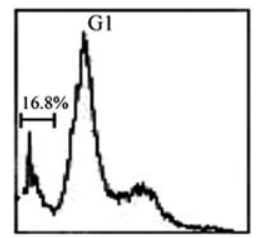

HCA

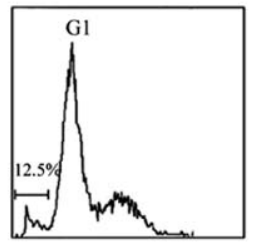

$\mathrm{H} \Delta 74$

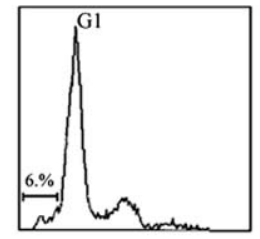

control
DNA conten

Fig. (2). Sub- $\mathrm{G}_{0} / \mathrm{G}_{1}$ DNA peak technique for determination of cell DNA content. Apoptotic cells appear to the left of the $G_{0} / G_{1}$ cell cycle region because of fragmentation of genomic DNA into hypodiploid DNA. The histograms show the results of cytometric analysis at $48 \mathrm{~h}$ p.i. of uninfected bursal cell cultures and infected bursal cell cultures.

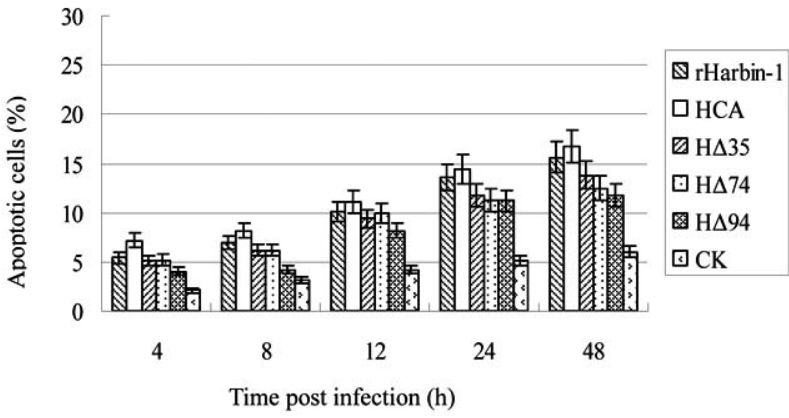

Fig. (3). Apoptosis 4-48 h after bursal cells were infected or not infected by the parental virus and virus mutants. The percentage of apoptotic cells was determined by the sub- $\mathrm{G}_{0} / \mathrm{G}_{1}$ DNA peak technique and flow cytometry analysis (means of three independent experiments, one sample each; error bars represent the standard deviation).

\section{Quantitative Real-Time PCR for All IBDV Mutants}

Quantitative nested RT-PCR was performed with the first PCR products as the template, producing the following results. The full-length cDNA clone of segment A (pRHA) was used as the standard plasmid, and serial $\log 10$ dilutions ranged from $10^{1}$ to $10^{8}$. The cDNAs were then used to determine the detectability and linearity of the assay. $\mathrm{Ct}$ values were plotted against the log of the input number of cDNA copies, and a linear relationship was observed with the amount of input RNA. Standard curves demonstrated a strong linear correlation between $10^{1}$ to $10^{8}$ copies $\left(\mathrm{R}^{2}=0.9979\right)$. These copies and $\mathrm{Ct}$ values are as follows: $10^{-1}$ : $10^{8}, 10.122 ; 10^{-2}: 10^{7}, 12.201 ; 10^{-3}: 10^{6}, 15.062 ; 10^{-4}: 10^{5}, 18.049$; $10^{-5}: 10^{4}, 20.092 ; 10^{-6}: 10^{3}, 23.073 ; 10^{-7}: 10^{2}, 26.046 ; 10^{-8}: 10^{1}$, 29.038 (Fig. 5).

Using SPSS 11.5, all data were subjected to a StudentNewman-Keuls one-way ANOVA, and $t$-tests showed that $\mathrm{H} \Delta 35$ had the highest replication efficiency among the examined virus mutants, $\mathrm{H} \Delta 74$ the lowest, and $\mathrm{H} \Delta 94$ and $\mathrm{HCA}$ were in between $\mathrm{H} \Delta 35$ and $\mathrm{H} \Delta 74$. There were marked differences in replication efficiencies between the virus mutants and the recovered wild-type virus rHarbin-1 $(p<$ 0.01 ) (Table 6). The results showed that although $\mathrm{H} \Delta 35$ had no promoter, it had higher replication efficiency than $\mathrm{H} \Delta_{74}$ and $\mathrm{H} \Delta_{94}$, which lacked a promoter and IRES. As the 
deletion length increased, replication efficiency decreased accordingly. However, H $\Delta 94$ was exceptional because it had a slightly higher replication efficiency than $\mathrm{H} \Delta 74$, suggesting that the nucleotide position 74-94 in segment A potentially has the ability to regulate virus replication.

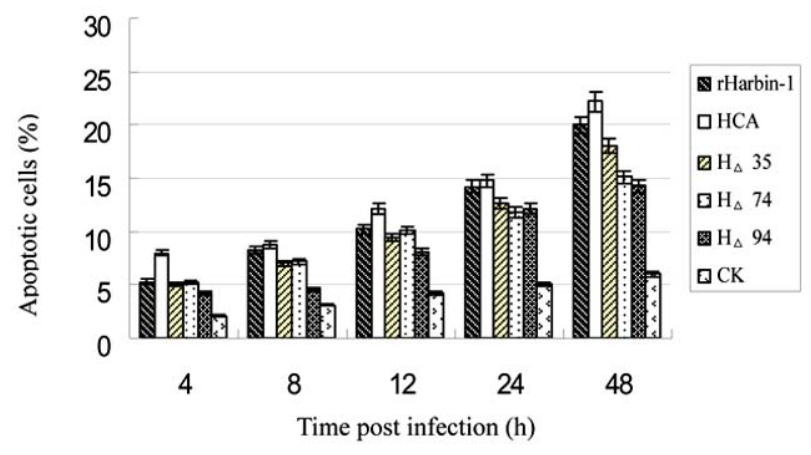

Fig. (4). Exponential change in the percentage of apoptotic bursal cells at $4-48 \mathrm{~h}$ p.i. in the infected and uninfected groups.

Table 5. Percentages of Apoptotic Cells Induced by IBDV Mutants

\begin{tabular}{|c|c|c|}
\hline Virus & Mean (\%) & $\mathbf{0 . 0 5}$ Variance \\
\hline \hline HCA & 12.3800 & $\mathrm{a}^{\text {q }}$ \\
\hline rHarbin-1 & 11.2133 & $\mathrm{~b}$ \\
\hline H $\Delta 35$ & 9.9600 & $\mathrm{c}$ \\
\hline H $\Delta 74$ & 9.6200 & $\mathrm{c}$ \\
\hline H $\Delta 94$ & 8.5267 & $\mathrm{~d}$ \\
\hline CK & 4.1533 & $\mathrm{e}$ \\
\hline
\end{tabular}

"The letters a-e represent the degree of variance in the following order: "a" is the largest and "e" is the smallest.

\section{DISCUSSION}

Apoptosis plays an important role in the processes of viral diseases, including AIDS and Newcastle disease [26]. While IBDV can induce apoptosis to different degrees in bursal cells, in the present study we determined that IBDV mutants can also induce apoptosis. IBDV deletion mutants had a decreased ability to induce apoptosis relative to rHarbin-1, suggesting that the $5^{\prime} \mathrm{NCR}$ plays a role in the regulation of apoptosis. The IBDV $5^{\prime} \mathrm{NCR}$ has cisregulatory elements for virus transcription and translation, such as promoter region, IRES, and a sequence similar to an enhancer.

Virus infection and replication, i.e., the pathological process of all infectious diseases, can induce apoptosis. Apoptosis is a genetic response of the host cells to IBDV infection; B cell apoptosis is a specific stage during IBDV replication and may prevent the diffusion of IBDV. Tham et al. demonstrated that virus replication and apoptosis were independent processes; they showed a negative correlation between apoptosis of chicken embryonic fibroblasts (CEFs) and Vero cells, but found no relation with titer after infection [12]. However, Jungmann et al. observed a relationship between apoptosis and virus replication [13]. Yao et al. reported that the percentage of apoptosis induced by the VP5 deletion mutant strain was less than that induced by a wild strain; the efficiency of replication was also lower in the mutant strain than in the wild strain [12, 27]. Our quantitative RT-PCR results showed that the rate of replication was in the order of rHarbin- $1>\mathrm{H} \Delta 35>\mathrm{HCA}>$ $\mathrm{H} \Delta 94>\mathrm{H} \Delta 74$, but the ability to induce apoptosis could be considered HCA $>$ rHarbin- $1>\mathrm{H} \Delta 35>\mathrm{H} \Delta 74>\mathrm{H} \Delta 94$. Only the abilities of rHarbin- 1 and $\mathrm{H} \Delta 35$ to induce apoptosis were clearly positively correlated with replication; however independent processes of replication and apoptosis were shown for $\mathrm{HCA}, \mathrm{H} \Delta 74$, and $\mathrm{H} \Delta 94$. We postulate that structural features of the NCR, especially in secondary structures, modulate the initiation of translation [28]. rHarbin-1 had the most stem-loop structure (Fig. 6), but had the highest replication efficiency and a higher percentage of apoptosis. It is possible that the stem-loop acted mutually for rHarbin-1 and became unstable, having a low free energy that did not impair translation.

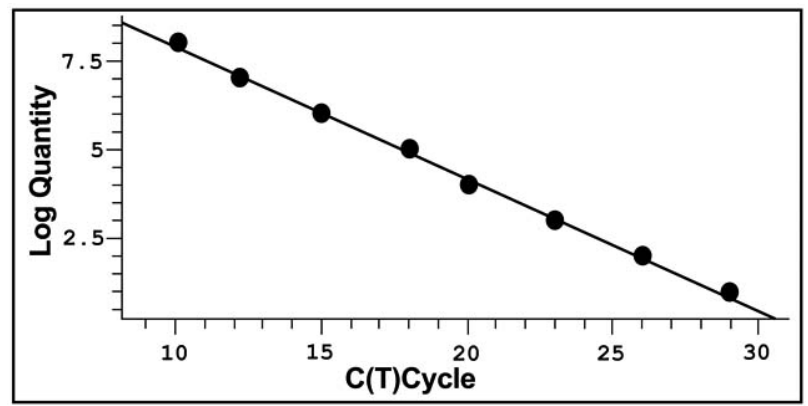

Fig. (5). Standard curve plot of log-10 diluted cDNA of segment A. Serial ten-fold dilutions of cDNA were amplified by RT-PCR. Each plot represents the mean of triplicate amplifications of each dilution. The regression equation was $\mathrm{y}=-0.3681 \mathrm{x}+11.572, \mathrm{R}^{2}=$ 0.9979 .

Table 6. Replication Efficiencies of the Virus Mutants and rHarbin-1, Determined by Quantitative Nested RTPCR

\begin{tabular}{|c|c|c|}
\hline \multicolumn{3}{|c|}{ Virus Mean (Copies) 0.01 Variance } \\
\hline \hline rHarbin-1 & 6211712640 & $\mathrm{a}^{\mathrm{f}}$ \\
$\mathrm{HCA}$ & 255548.67 & $\mathrm{c}$ \\
$\mathrm{H} \Delta 35$ & 735277.63 & $\mathrm{~b}$ \\
$\mathrm{H} \Delta 74$ & 58434.224 & $\mathrm{e}$ \\
$\mathrm{H} \Delta 94$ & 98559.650 & $\mathrm{~d}$ \\
$\mathrm{CK}$ & 0 & $\mathrm{f}$ \\
\hline
\end{tabular}

The letters a-e represent the degree of variance in the following order: "a" is the largest and "e" is the smallest.

The chimeric IBDV HCA induced the largest percentage of apoptosis in our study. The regulating element may have changed after the NCR of the vvIBDV was replaced by the corresponding NCR of the mildly virulent Cj801; the cells may have been adaptable to non-lymphocytes, resulting in the apoptosis of non-lymphocytes and a higher percentage of apoptosis.

$\mathrm{H} \Delta 35$ had a higher replication efficiency and a greater potential ability to induce apoptosis than did $\mathrm{H} \Delta 74$ and $\mathrm{H} \Delta 94$. The secondary structure of $\mathrm{H} \Delta 35$, in which the promoter was deleted, was similar to that of the HCA $5^{\prime}$ 


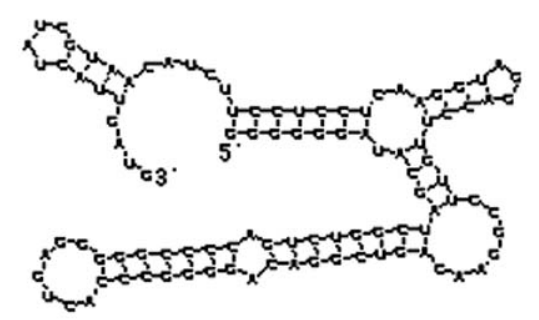

Harbin-1

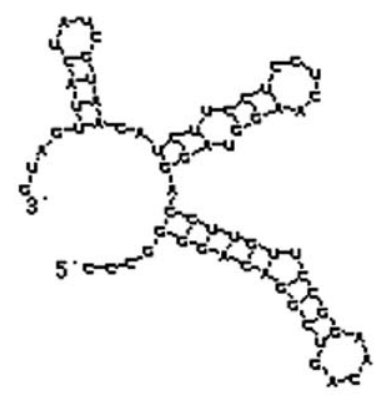

$\mathrm{H} \square 35$

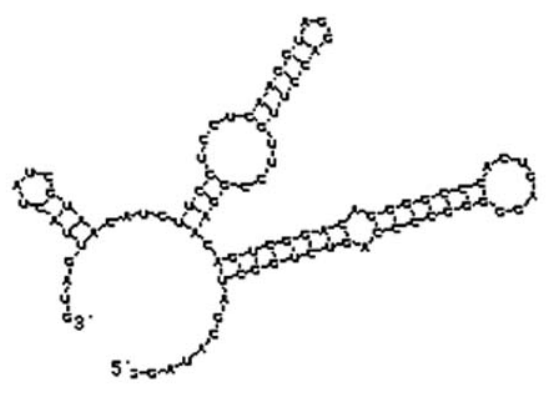

HCA

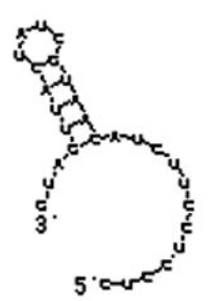

$\mathrm{H} \square 74$

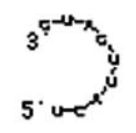

$\mathrm{H} \square 94$

Fig. (6). The secondary structure of the 5' NCR mRNA of Harbin-1 and the mutants (predicted by DNAstar).

NCR, but $\mathrm{H} \triangle 35$ had less stem-loop structure than did HCA (Fig. 6). The $\mathrm{G}+\mathrm{C}$ content at position 35 was up to $68 \%$ and the stem-loop structure was rather stable; after deleting position 35, there was less stem-loop structure, which could lead to the convenient binding of the 40 s ribosomal-initiation complex with the template, increasing the efficiency of transcription and translation of the IBDV genome. $\mathrm{H} \Delta 35 \mathrm{had}$ a weaker ability to induce apoptosis than did HCA and rHarbin-1, suggesting a correlation between virus replication and secondary structure.

The secondary structure of $\mathrm{H} \Delta 74$ was "pot-shaped" with less stem-loop structure; $\mathrm{H} \Delta 74$ had the least replication efficiency, possibly because of the deletion of the enhancer. However, it had a higher percentage of apoptosis than did $\mathrm{H} \Delta 94$, which suggests that both $\mathrm{H} \Delta 74$ and $\mathrm{H} \Delta 94$ regulate apoptosis via a yet unknown mechanism.

$\mathrm{H} \Delta 94$, in which most of the NCR was deleted, had the least capability to induce apoptosis. A possible explanation is that $\mathrm{H} \Delta 94$ lacked a promoter at position 32 and IRES at position 81 ; this would interfere with the initial complex scan and recognition of the initial site for protein synthesis, thereby affecting the initiation of transcription and expression of proteins VP2 and VP5, and thus slowing down the rate of apoptosis. These results suggest that other mechanisms are involved in apoptosis and remain to be investigated.

In this study, acridine orange and ethidium bromide double staining was adopted to observe apoptosis. The change in the number of apoptotic bursal cells induced by IBDV mutants corresponded with results of flow cytometry assays, in accordance with the results of Vasconcelos and Ojeda $[9,11]$. However, there was a slight difference in the time interval during which cells exhibited apoptosis and endurance.

\section{CONCLUSION}

The promoter region and IRES increase the ability to induce apoptosis and replication efficiency. Furthermore, the region between the promoter and IRES, 74-94 nucleotides in segment $\mathrm{A}$, has the potential ability to regulate virus replication. 


\section{ACKNOWLEDGEMENTS}

We gratefully acknowledge Professor Zhao Deming of the National Animal TSE Lab, China Agricultural University, for his assistance in the quantitative real-time PCR experiment. This study was supported by grant no. 9893290 from the National Natural Science Foundation of China.

$$
\begin{aligned}
& \text { ABBREVIATIONS } \\
& \begin{array}{ll}
\mathrm{CR} & =\text { Coding region } \\
\mathrm{DMEM} & =\text { Dulbecco's modified Eagle's medium } \\
\mathrm{IBDV} & =\text { Infectious bursal disease virus } \\
\mathrm{IRES} & =\text { Internal ribosome entry site } \\
\mathrm{NCR} & =\text { Non-coding region } \\
\mathrm{PCR} & =\text { Polymerase chain reaction } \\
\mathrm{TdT} & =\text { Deoxynucleotidyl transferase } \\
\mathrm{SPF} & =\text { Specific-pathogen-free } \\
\mathrm{VVIBDV} & =\text { Very virulent IBDV }
\end{array}
\end{aligned}
$$

\section{REFERENCES}

[1] Lemon SM, Honda M. Internal ribosome entry site within the RNA genomes of hepatitis C virus and other flaviviruses. Semin Virol 1997; 8: 274-88.

[2] Ismail NM, Saif YM, Moorhead PD. Lack of pathogenicity of five serotype 2 infectious bursal disease viruses in chickens. Avian Dis 1988; 32(4): 757-9.

[3] Nieper H, Müller H. Susceptibility of chicken lymphoid cells to infectious bursal disease virus does not correlate with the presence of specific binding sites. J Gen Virol 1996; 77(6): 1229-37.

[4] Le SY, Chen JH, Sonenberg N, Jacob VMJ. Conserved tertiary structure element in the 5'nontranslated region of cardiovirus, aphthovirus and hepatitis A virus RNAs. Nucleic Acids Res 1993; 21(10): 2445-51.

[5] Hagen M, Chung TD, Butcher JA, Krystal M. Recombinant influenza virus polymerase: requirement of both $5^{\prime}$ and $3^{\prime}$ viral ends for endonuclease activity. J Virol 1994; 68(3): 1509-15.

[6] Scheef G, Fischer N, Flory E, Schmitt I, Tönjes RR. Transcriptional regulation of porcine endogenous retroviruses released from porcine and infected human cell by heterotrimeric protein complex NF2Y and impact of immunosuppressive drugs. J Virol 2002; 76(12): 12553-63.

[7] Mundt E, Müller H. Complete nucleotide sequences of 5'- and 3 '-noncoding regions of both genome segments of different strains of infectious bursal disease virus. Virology 1995; 209: 10-8.

[8] Dobos P. Protein-primed RNA synthesis in vitro by the virionassociated RNA polymerase of infectious pancreatic necrosis virus. Virology 1995; 208(1): 19-25.
Ojeda F, Skardova I, Guarda M I, Ulloa J, Folch H. Proliferation and apoptosis in infection with Infectious Bursal Disease Virus: a flow cytometric study. Avian Dis 1997; 41: 312-6.

[10] Vasconcelos AC, Lam KM. Apoptosis induced by infectious bursal disease virus. J Gen Virol 1994; 75: 1803-6.

[11] Vasconcelos AC, Lam KM. Apoptosis in chicken embryos induced by the infectious bursal disease virus. J Comp Pathol 1995; 112: 327-38.

[12] Tham KM, Moon CD. Apoptosis in cell cultures induced by infectious bursal disease virus following in vitro infection. Avian Dis 1996; 40: 109-13.

[13] Jungmann A, Nieper H, Müller H. Apoptosis is induced by infectious bursal disease virus replication in productively infected cells as well as in antigen negative cells in their vicinity. J Gen Virol 2001; 82: 110715 .

[14] Fernandez-Arias A, Martinez S. The major antigenic protein of infectious bursal disease virus, VP2, is an apoptotic inducer. J Virol 1997; 71: 8014-8.

[15] Yao K, Vakharia VN. Induction of apoptosis in vitro by the $17-\mathrm{kDa}$ nonstructural protein of infectious bursal disease virus: possible role in viral pathogenesis. Virology 2001; 285: 50-8.

[16] Rodríguez-Lecompte JC, Niño-Fong R, Lopez A, Markham FRJ, Kibenge FS. Infectious bursal disease virus (IBDV) induces apoptosis in chicken B cells. Comp Immunol Microbiol Infect Dis 2005; 28(4): 321-37.

[17] Frohman MA, Dush MK, Martin GR. Rapid production of full-length cDNAs from rare transcripts: amplification using a single gene-specific oligonucleotide primer. Proc Natl Acad Sci USA 1988; 85(23): 89989002.

[18] Sambrook J, Russell DW. Molecular cloning. 3rd ed. Cold Spring Harbor Laboratory Press: Cold Spring Harbor 2001.

[19] Wang HY. Dissertation for China Agricultural University 2002.

[20] Huang GM. Dissertation for China Agricultural University 1999.

[21] Eterradossi N, Toquin D, Rivallan G, et al. Modified activity of a VP2located neutralizing epitope on various vaccine, pathogenic and hypervirulent strains of infectious bursal disease virus. Arch Virol 1997; 142: $255-70$.

[22] Lam KM. Apoptosis in chicken embryo fibroblasts causes by Newcastle disease virus. Vet Microbiol 1995; 47: 357-63.

[23] Telford WG, King LE, Fraker PJ. Rapid quantitation of apoptosis in pure and heterogeneous cell populations using flow cytometry. J Immunol Methods 1994; 172: 1-16.

[24] Duke RC, Cohen JJ. Morphology and biochemical assays of apoptosis. In: Coligan JE, Kruisbeek AM, Margulies DH, Shevach EM, Strober W, Eds. Current protocols in immunology. New York: John Wiley \& Sons 1992; pp. 3.17.1-3.17.16.

[25] Hierholzer JC, Killington RA. Virus isolation and quantitation. In: Brian WJM, Hillar OK, Eds. Virology methods manual. San Diego: Academic Press 1996; pp. 39-40.

[26] Stewart SA. Human immunodeficiency virus type 1 induces apoptosis is following cell cycle arrest. J Virol 1997; 7: 5579-92.

[27] Yao K, Goodwin MA. Generation of a mutant infectious bursal disease virus that does not cause bursal lesions. J Virol 1998; 72: 2647-54.

[28] Kozak M. Structure features in eukaryotic mRNA that modulates the initiation of translation. J Biol Chem 1991; 266: 19867-70. 